\title{
URGENSI PENGELOLAAN PARIWISATA KAMPUNG HERITAGE KAJOETANGAN MALANG
}

\author{
Moch. Nurfahrul Lukmanul Khakim ${ }^{1 *}$, Mariatul Ulfa Utami Putri ${ }^{1}$, Wikan \\ Saktianto $^{1}$, Nur Andari Budi ${ }^{1}$
}

Diterima 2 Februari 2019, Dipublikasikan 30 April 2019

CPenulis (2019)

\begin{abstract}
Malang City as one of the cities of cultural tourism and history in East Java has its own charm, one of which is village tourism. Village tourism with the feel of thematic cult ural entertainment named Heritage Kayutangan Village has not been well managed since it was founded a year ago. This research method is qualitative with observation and interviews. Kayutangan Malang Heritage Village has a unique appeal with the classic nuances of the past. Kampung Kayutangan offers several facilities such as village lines, old house visits, photo spots, traditional game spots, past photo galleries, antique galleries and ancient culinary variety. The potential of Heritage Kayutangan Village has not been managed properly. Two historical tourism management strategies offered are setting appropriate city government policies and effective promotions to increase tourism attractiveness.
\end{abstract}

\section{Keywords}

urgency, Kampung Heritage Kajoetangan, management

\section{PENDAHULUAN}

Kampung Heritage Kajoetangan Malang terletak di sekitar pusat Kota Malang yaitu di Jalan Jend Basuki Rachmat Gg. VI, Kauman, Klojen. Sejak ini resmi dibuka pada 22 April 2018, Kampung Kayutangan ini ditetapkan sebagai kawasan budaya (heritage) oleh pemerintah Kota Malang (Radar Malang, 2018). Kayutangan memang dapat dikatakan sebagai kawasan yang bersejarah karena pada era kolonial Belanda, kawasan ini menjadi jalan pusat. Hal ini dibuktikan dengan peninggalan yang sekarang dapat ditemui di kawasan ini yaitu bangunan-bangunan peninggalan Belanda masih dipertahankan bentuk aslinya terutama bentuk asli rumah di perkampungan Kayutangan. Kampung Kayutangan ini menawarkan wisata budaya yang bermuatan edukasi sejarah dengan memperlihatkan arsitektur rumah peninggalan kolonial Belanda yang masih terjaga hingga saat ini. Tidak hanya arsitektur bangunan, peralatan atau barang-barang kuno juga tersedia seperti sepeda ontel, peralatan masak, lampu, jendela, kamera, telepon dan perabotan rumah lainnya. Selain itu kampung Kayutangan juga masih menyimpan banyak sisa peradaban masa lalu berupa bangunan pertokoan, makam Eyang Honggo Kusumo, kuburan Tandak, Pasar Krempyeng, irigasi Belanda, saluran air, tangga seribu dan titik lainnya yang memiliki nilai sejarah yang tinggi di Kota Malang. Atmaja (2002:119) menyatakan kawasan pariwisata merupakan kawasan dengan luas tertentu yang dibangun atau

\footnotetext{
${ }^{1}$ Jurusan Sejarah Fakultas Ilmu Sosial Universitas Negeri Malang moch.nurfahrul.fis@um.ac.id
} 
disediakan untuk memenuhi kebutuhan pariwisata. Berdasarkan potensi di atas, Kampung Heritage Kajoetangan layak menjadi kawasan pariwisata yang menarik di Malang.

Kampung Heritage Kajoetangan yang potensial ini perlu dikelola sesuai dengan UU yang berlaku. Sejak diberlakukannya UU no. 22 tahun 1999 yang kemudian disempurnakan atau diganti menjadi UU No. 32 tahun 2004 tentang pemerintah daerah, sesungguhnya sudah lebih menjamin cita-cita penegakan prinsip-prisip demokrasi yang menjunjung tinggi pluralitas, transparansi, akuntabilitas, dan berbasis pada kemmapuan lokal. Hakikat otonomi daerah adalah kesempatan seluas-luasnya bagi pemerintah daerah untuk meningkatkan kesejahteraan masyarakatnya, tidak hanya mengandalkan dana perimbangan pusat dan daerah tetpai juga menggali potensi sumber pendapatan asli daerah dengan tetap memperhatikan prinsip-prinsip keadilan dan keberlanjutan. Namun, pemerintah setempat belum secara optimal menggali sumbersumber pendapatan di daerahnya. Salah satu sumber pendapatan daerah yang penting adalah pariwisata. Kampung Heritage Kajoetangan ini memiliki daya tarik yang dapat dikelola dengan maksimal untuk pariwisata.

Simanjuntak, dkk (2017:165) wisata budaya adalah perjalanan yang dilakukan atas dasar keinginan untuk memperluas pandangan atau mempelajari kebiasaan dan adat istiadat, cara hidup, budaya dan seni, serta kegiatan bermotif kesejarahan sekelompok orang dengan melakukan peninjauan langsung ke lokasi sumbernya. Kampung Heritage Kajoetangan ini termasuk wisata budaya yang memperkaya aneka wisata budaya di Malang seperti Sentra Keramik Dinoyo, Candi Badut, Museum Mpu Purwa dan lain sebagainya. Sebagai destinasi wisata baru, Kampung Heritage Kajoetangan ternyata belum dikelola dengan baik. Penelitian kali ini bertujuan untuk mengidentifikasi potensi dan risiko untuk mengeksplorasi peluang dan solusi penting dalam pengelolaan Kampung Heritage Kajoetangan menjadi lebih baik di masa depan.

\section{METODE}

Metode penelitian kualitatif dipakai dalam penelitian kali ini dengan cara observasi langsung, dokumentasi dan wawancara terhadap narasumber. Metode tersebut digunakan karena dianggap metode yang tepat dalam mencari dan mengodal data yang cukup akurat. Pelaksanaan observasi Kampung Heritage Kajoetangan dengan menelusuri seluruh titik destinasi sejumlah tiga puluh spot. Selain melakukan observasi, peneliti juga melakukan dokumentasi dan wawancara. Peneliti melakukan wawancara dengan salah satu penggagas Kampung Heritage Kajoetangan . Peneliti juga menggunakan sumber-sumber pustaka lain yang relevan untuk menguatkan analisis peneliti mengenai edukasi sejarah.

\section{HASIL DAN PEMBAHASAN}

Daerah Kayutangan telah ditetapkan sebagi kawasan wisata budaya (heritage) oleh Pemerintah Kota Malang. Asal-usul nama Kayutangan menurut kesaksian warga asli Malang yaitu Oei Hiem Hwie dan A. V. B. Irawan, di sepanjang jalan Kayutangan dulu setiap kanan-kiri ditanami pohon-pohon yang daunnya berbentuk telapak tangan yang mengembang. Pohon jenis ini juga ditanam di Taman Indrakila tapi kini sudah tidak ada lagi (Widodo dkk, 2006:220). Walaupun pohon legendaris itu sudah tidak bisa ditemui lagi, Kampung Heritage Kajoetangan ini masih menyimpan cagar purbakala atau bangunan 
bersejarah di Kota Malang. Bangunan-bangunan atau rumah warga ini kental dengan arsitektur kolonial (Belanda). Sepanjang jalan Kayutangan juga merupakan poros ekonomi Kota Malang sejak zaman Belanda sampai sekitar era tahun 1990an. Dalam kampung Kayutangan masih banyak menyisakan kejayaan masa lalu berupa bangunan toko, Makam Eyang Honggo Kusumo, Kuburan Tandak, pasar krempyeng, irigasi Belanda, saluran air, tangga 1000, rumah jaman kolonial dan beberapa spot menarik lainnya. Hal tersebut mempunyai cerita tersendiri dan bisa menjadi komoditi dalam menghadirkan wisata di tengah Kota Malang.

Wahab (2003:6) menyatakan pariwisata budaya adalah perjalanan untuk memperkaya wawasan dan ilmu serta untuk memuaskan kebutuhan hiburan tentang negara lain atau menghadiri pameran-pameran, perayaan-perayaan adat, tempat-tempat cagar alam, cagar purbakala, dan lain-lain. Kawasan Kayutangan termasuk pariwisata budaya yang berada di kompleks yang terletak di sepanjang Jalan Celaket, mulai dari Kantor PLN yang sekarang sampai dengan Gereja Kayutangan yang bermodel pertokoan Eropa berbentuk kubus bertingkat. Pada zaman dulu merupakan kompleks rekreasi kolonial kebanggaan Kota Malang. Pada era kolonial, kawasan ini yang hanya boleh dikunjungi oleh kalangan atas dan pribumi dilarang masuk ke kawasan kompleks tersebut (Times Indonesia, 2019). Sedangkan untuk pekerja dan pengelolanya kebanyakan dari para pribumi dan etnis Tionghoa, bagi para pekerja di berikan perumahan di belakang kompleks pertokoan yang disebut kampung Kayutangan hingga saat ini yang terletak di sepanjang Jalan Basuki Rahmat. Awalnya kampung ini merupakan area saluran air untuk mencegah banjir karena lokasinya yang tertutup oleh kawasan pertokoan maka pekerja diperbolehkan membangun rumah triplek (anyaman bambu) hingga pada tahun 1930 dibangun rumah-rumah model Indies yang ditempati oleh para Londo. Namun, semenjak tahun 1950-an kampung ini telah dijadikan perkampungan yang tidak tertata oleh para pendatang atau para penduduk sekitar yang membeli dari para pewaris rumah indies yang kebanyakan berasal dari Etnis Tionghoa. Deskripsi sejarah yang diperoleh dari Ketua Rukun Warga Kayutangan selaku narasumber itu menjadikan Kampung Heritage Kajoetangan memiliki daya tarik wisata sejarah yang menarik (Gambar 1).

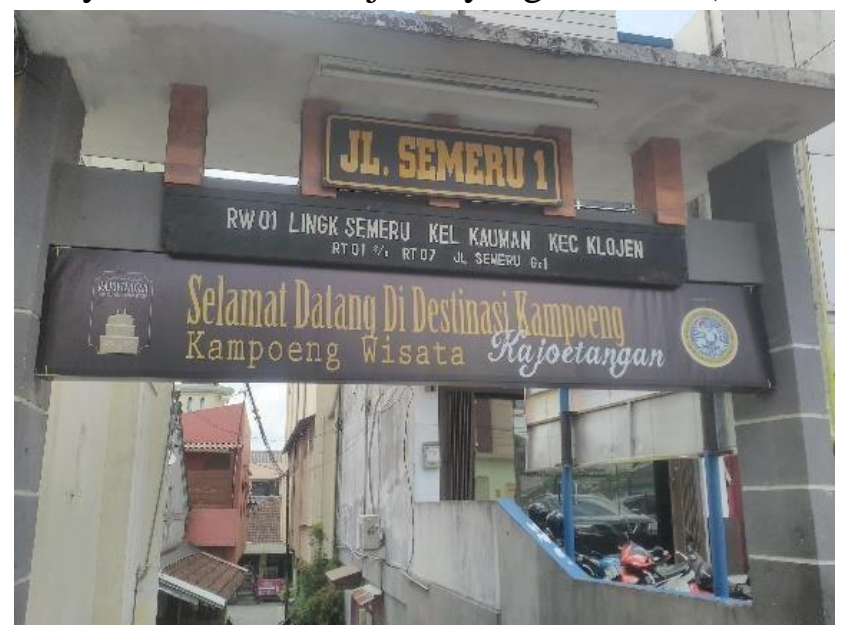

Gambar 1. Pintu masuk Destinasi Kampung Heritage Kajoetangen (Khakim . 2019)

Daya tarik wisata yang ditonjolkan di Kampung Heritage Kajoetangan adalah wahana berfoto dan bangunan tua. Utama $(2017: 141)$ daya tarik wisata adalah segala sesuatu di 
suatu tempat yang memiliki keunikan, keindahan, kemudahan dan nilai yang berwujud keanekaragaman kekayaan alam maupun buatan manusia yang menarik dan mempunyai nilai untuk dikunjungi dan dilihat wisatawan. Salah satunya pada saat memasuki gang yang terdapat di Jalan Kawi terdapat gambar peta dari Kampoeng Wisata Heritage Kojoetangan. Sepanjang jalan gang yang lurus terdapat Rumah Foto Galeri Antik, Rumah Jamu, Galeri Pak Eko Antik, Galeri Pak Udin, lalu ada Masjid Tua dan Rumah Punden. Di depan rumah Punden ada pertigaan kemudian belok kanan, di situ terdapat Gubug Ningrat, Rumah Jacoeb, Rumah Kaca Mata dan Galeri Abbas Akub. Ada banyak lagi fasilitas lainnya seperti Tangga 1000 Belanda, Pojok Dolanan, Kuburan Tanduk, Rumah Mbah Ndut, Makam Eyang Honggo Kusumo, Rumah Nyik Aisyah, Priambodo House of Kebaya, Rumah Tua, Rumah Pak Sakirman, Rumah Rindu, Pintu Jengki, Rumah Penghulu, Rumah Cerobong, Rumah Pak Hasan, Rumah Namsin, Pintu Rolak, Rumah Pijat dan Rumah Kartini. Semua informasi fasilitas tersebut sudah ada denahnya pada peta (Gambar 2) di dekat gang Jalan Kawi. Informasi ini cukup menarik untuk dibaca oleh wisatawan karena jika sejarah tidak menarik untuk dibaca, maka tidak akan ada minat untuk mempelajari sejarah (Khakim, 2016:92-93).

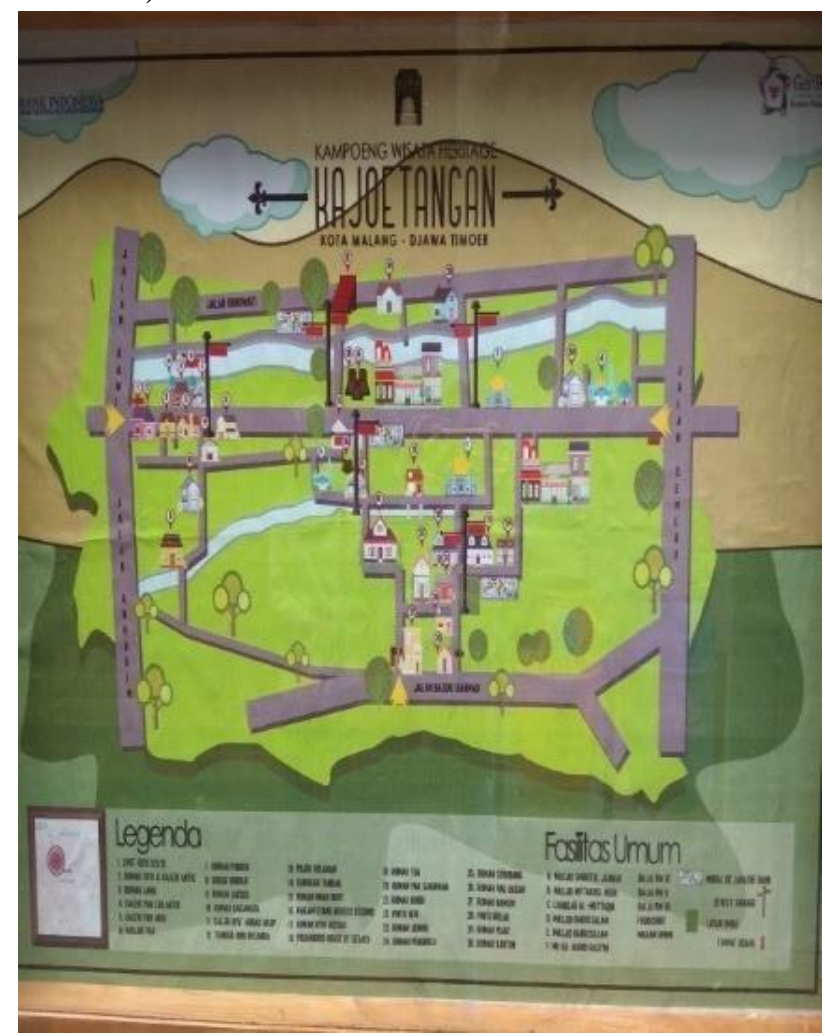

Gambar 2. Peta Kampung Wisata Heritage Kayutangan (Khakim. 2019)

Wahan-wahana berfoto yang terdapat di Kampung Heritage Kajoetangan merupakan buatan dari warga sekitar agar tempat di situ terlihat klasik. Selain dari spot foto buatan warga, rumah rumah warga yang masih sangat kental dengan arsitektur kolonial (Belanda) juga dapat dibuat sebagai spot foto/wahana berfoto. Mungkin karena Kampung Heritage Kajoetangan baru berdiri, masih sekitar satu tahun jadi fasilitas-fasilitas pendukung yang terbatas membuat Kampung Heritage Kajoetangan menjadi kurang menarik di mata para wisatawan. Selain itu, tidak ada pemandu wisata (guide) yang 
siaga dan gratis untuk memandu para wisatawan agar lebih mengetahui nilai sejarah dari kampung Heritage Kajoetangan. Ditambah kurangnya pembinaan untuk warga agar lebih mengetahui nilai sejarah dari Kampung Heritage Kajoetangan. Warga-warga dari Kampung Heritage Kajoetangan juga membutuhkan aspirasi-aspirasi untuk membuat Kampung Heritage Kajoetangan menjadi lebih menarik tanpa harus menghilangkan nilai sejarah yang ada di dalamnya. Selain itu warga juga membutuhkan kerjasama dengan pemangku kebijakan, mahasiswa dan seniman seniman untuk mempercantik Kampung Heritage Kajoetangan tersebut berupa lukisan-lukisan bernuansa Kolonial atau pun topengtopeng Malangan. Pengadaan pameran-pameran budaya di Kampung Heritage Kajoetangan juga akan menarik wisatawan untuk mengunjungi wisata budaya ini. Keberadaan agenda acara rutin yang dapat diakses oleh wisatawan akan mempermudah calon wisatawan dalam mencari informasi tentang daerah tujuan wisata (Purnomo, A \& N Ruja, I \& Irawan, Listyo. 2018)

Urgensinya dalam pengelolahan kampung wisata Kayutangan, warga sekitar tidak terlalu terlibat di dalamnya. Salah satu pengelolanya yang bernama Rizal tertarik menjadikan kampung Kayutangan menjadi tempat berburu berfoto yang menarik bagi generasi milenial. Rizal dan kelompoknya telah memasang peta di dekat Pasar Krempyeng yang berfungsi menunjukkan skema tur sekaligs informasi sekilas mengenai sudutsudut menarik di Kampung Heritage Kajoetangan. Pengelola memasang tiket masuk mulai dari Rp 5.000 dengan bonus kartu pos bergambar perempuan berpakaian ala Eropa berlatar Kampung Kayutangan masa kini berwarna hitam-putih tanpa fasilitas lain. Sedangkan tiket khusus seharga Rp 800.000 menawarkan fasilitas lengkap berupa dua pemandu, acara prasmanan, ikut permainan anak-anak, pertunjukantarian dan masuk delapan bangunan rumah Indies. Selain itu, ada tarif yang dikhususkan untuk agensi model dengan konfirmasi seharga Rp 100.000 per spot foto. Sedangkan tanpa koordinasi atau tanpa dipesan terlebih dahulu minimal tiga hari sebelumnya, maka agensi foto hanya bisa memanfaatkan sisi pinggir sungai kampung seperti kampung pada umumnya.

Damanik (2005:23) menyatakan peluang kerja bagi masyarakat miskin dapat diperluas dengan cara merekrut tenaga kerja dalam kegiatan kepariwisataan. Berdasarkan observasi, warga yang tinggal di Kampung Heritage Kajoetangan berasal dari berbagai latar belakang ekonomi, kebanyakan masyarakat menengah ke bawah. Pemberlakuan berbagai tarif paket wisata di Kampung Heritage Kajoetangan ini diharapkan mampu menyerap angka pengangguran di sekitar kawasan wisata. Hal ini belum berjalan optimal karena terhambat dengan tata kelola kampung wisata. Pengelolaan kampung wisata ini hanya bersifat episodikal selama terdapat acara tertentu dari Penyelenggara Pariwisata Kota Malang sehingga koordinasinya tidak terlalu jelas.

Kampung Kayutangan memiliki peluang sebagai tempat wisata dan legitimasi untuk mencegah penggusuran oleh pemerintah untuk kepentingan tata kota. Memang terdapat beberapa rumah lama akan tetapi para penghuninya kebanyakan adalah pekerja serabutan dan pedagang toko di kawasan Pasar Besar, juga terdapat alumnus Universitas Unair Cabang Malang yang bekerja sama dengan pengelola kampung. Peluang yang ditawarkan sumber daya budaya ini adalah citra Kota Malang sebagai tempat wisata budaya yang memiliki peninggalan bangunan kolonial sebagai kekuatan meningkatkan wisatawan. Dengan adanya keinginan narsistik pengunjung, kampung ini sesuai sebagai tempat 
berfoto atau sebagai setting tempat film bertema tahun1920-an sampai 1970-an. Urgensi yang ada dari kampung ini adalah limbah rumah tangga yang terbuang ke saluran irigasi yang dapat bertambah ketika datangnya pengunjung. Selain itu, tanpa adanya pengaturan dan pengawasan lebih lanjut, kampung ini dapat menjadi wisata dengan konotasi lain meskipun kemungkinan kecil terjadi karena lokasi wisatanya yang tidak terlalu ramai.

Kampung Kayutangan memiliki nilai ekonomis sebagai penarik wisatawan untuk menjelajah kampung sebagaimana pandangan stereotip mengenai kampung di sekitar saluran irigasi atau sungai. Meskipun hanya terdiri dari serangkaian rumah-rumah Indies dan semi- permanen, paling tidak terdapat nuansa nostalgia yang ingin dirasakan pengunjung dari Kota Malang. Secara edukatif nilai yang dapat diambil adalah bagaimana masyarakat Kota Malang kelas menengah ke bawah mendapatkan barang "mewah" seperti radio atau keramik atau melakukan kegiatan ekonomi melalui toko-toko kecil atau yang disebut sebagai Pasar Krempyeng. Terdapat pula koleksi seni milik penghuni salah satu rumah yaitu milik Mr. Jacob yang memamerkan karya lukisannya pada awal abad ke-20 M. Selain nilai-nilai ekonomis belum diungkapkan nilai sosial baik religius ataupun kesenian yang menonjol dari kampung ini selain terdapat sanggar seni yang jarang digunakan. Nilai yang berwujud fisik lebih ditonjolkan karena mereka dapat dijelaskan dengan mudah. Singkatnya belum terdapat nilai yang lebih menarik daripada nilai wisata.

Rachman (2014: 156) mengungkapkan dua hal efektif untuk manajemen pariwisata dalam kawasan bersejarah yaitu pertama, kebijakan publik dan tindakannya dalam melestarikan sumber daya sejarah serta mengatur perubahan penggunaan lahan di pusat kota. Kebijakan pemerintah kota Malang tampak pada peresmian wisata ini. Kemudahan akses dan tranportasi menuju wisata ini disebabkan karena lokasinya di dekat pusat kota. Hal ini perlu menjadi perhatian pemerintah karena rentan kemacetan, terutama saat hari libur. Kebijakan penting yang perlu diambil oleh Pemerintah Kota adalah melakukan kajian sejarah, antropologi, sosial dan arkeologi lebih mendalam untuk mengeksplorasi potensi-potensi lain dari Kampung Heritage Kajoetangan. Hal ini penting untuk meningkatkan daya tarik wisata Kampung Heritage Kajoetangan ke depan supaya tidak hanya menjadi euforia budaya yang berumur singkat. Pemerintah kota perlu melakukan tindakan pelestarian secara serius dengan pengusulkan dan menetapkan kawasan ini sebagai Cagar Budaya yang sah sesuai undang- undang RI No. 11 2010. Kedua, promosi dan pemasaran destinasi sejarah adalah sebuah proses yang dilaksanakan untuk kepentingan sektor swasta. Promosi Kampung Heritage Kajoetangan belum dilaksanakan secara maksimal. Pemasaran yang dilakukan hanya sebatas media sosial dan internet. Pengelola Kampung Heritage Kajoetangan perlu mengadakan kegiatan rutin seperti diskusi kesejarahan atau sarasehan, jelajah kota, permainan tradisional, lomba foto dan video untuk menghidupkan edukasi sejarah yang kontekstual untuk warga kota Malang maupun target wisatawan yang lebih luas lagi. Promosi yang dilakukan bekerjasama dengan pemerintah kota untuk dimasukkan dalam lama dan media sosial resmi Kota Malang dan publikasi media massa lainnya. Pengelola Kampung Heritage Kajoetangan juga perlu mengadakan kerja sama dengan pihak swasta untuk melakukan promosi dan pemasaran yang lebih luas. Langkah promosi dan pemasaran yang paling penting adalah partisipasi aktif warga yang tinggal di kawasan wisata sebagai bagian penting yang paling 
vital dalam pengembangan dan pelestarian Kampung Heritage Kajoetangan secara berkelanjutan.

\section{KESIMPULAN}

Kampung Kayutangan memiliki peninggalan rumah-rumah klasik yang memiliki potensi destinasi pariwisata yang sudah diresmikan sebagai Kampung Heritage Kajoetangan sejak April tahun 2018. Pengelolaannya sayangnya masih belum terlalu jelas sehingga kampung ini bahkan belum diketahui oleh warganya sebagai destinasi pariwisata. Fasilitas yang ditawarkan oleh pihak manajemen berupa wahana-wahana foto, papan informasi mengenai sekilas info beberapa rumah tertentu, pasar krempyeng sebagai tempat penyedia makanan dan minuman, juga denah untuk menunjukkan arah. Fasilitas-fasilitas tersebut memang dapat diakses dengan mudah oleh pengunjung, namun pengunjung baru akan menikmati wisata dari Kampung Kayutangan apabila telah memesan terlebih dahulu kepada pihak manajemen beberapa hari sebelumnya sehingga objek wisata ini lebih mirip galeri barang-barang antik yang bahkan pengunjung tidak mengetahui bagaimana seharusnya kampung wisata ini berjalan selain.

\section{UCAPAN TERIMA KASIH}

Ucapan terimakasih peneliti haturkan kepada Bapak Muhammad Rizal, Ketua Pokdarwis Kayutangan, dan Bapak Iwan, narasumber yang telah memberikan sekilas sejarah Kampung Kayutangan dan bagaimana kampung wisata ini ingin mempertahankan eksistensinya sebagai objek pariwisata.

\section{DAFTAR PUSTAKA}

Atmaja, Ida Bagus Yoga. 2002. Ekowisata Rakyat: Lika-Liku Ekowisata di Tenganan, Pelaga, Sibetan dan Nusa Ceningan Bali. Denpasar: Wisnu

Damanik, Janianton. 2005. Penanggulangan Kemiskinan melalui Pariwisata: Dari Konsep menuju Implementasi. Damanik, Janianton, dkk. Penanggulangan Kemiskinan Melalui Pariwisata (17-33), Yogyakarta: Penerbit Kepel Press

Khakim, Moch. Nurfahrul Lukmanul. 2019. Telaah Penulisan Karya Sastra sebagai Refleksi Sumber Pembelajaran Sejarah. Jurnal Sejarah dan Budaya, X, No. 1, Juni 2016 (Hal. 89-94)

Khakim, Moch. Nurfahrul Lukmanul. 2019. Pengumpulan data lapangan di Kampung Heritage Kajoetangen.

Iwan, Ketua RW IX Kayutangan, Jl. Jend Basuki Rachmat Gg. VI, Kauman, Klojen.

Pemerintah Indonesia. 1999. Undang-Undang No. 22 Tahun 1999 Tentang Pemerintah Daerah. Lembaran RI Tahun 1999 No. 22. Jakarta: Sekretariat Negara.

Pemerintah Indonesia. 2004. Undang-Undang No. 32 Tahun 2004 Tentang Pemerintahan Daerah. Lembaran RI Tahun 2004 No. 32. Jakarta: Sekretariat Negara.

Pemerintah Republik Indonesia. 2010. Undang-Undang No. 11 Tahun 2010 Tentang Cagar Budaya 
Purnomo, A \& N Ruja, I \& Irawan, Listyo. 2018. Typology of tourist Bromo Tengger Semeru National Park as a basic planning integrated tourism design. IOP Conference Series: Earth and Environmental Science. 145. 012015. 10.1088/17551315/145/1/012015.

Rachman, Arif F. 2014. Geografi Pariwisata Jawa dan Bali. Jakarta: Media Bangsa

Simanjuntak, Bungaran Antonius, dkk. 2017. Sejarah Pariwisata Menuju Perkembangan Pariwisata Indonesia. Jakarta: Yayasan Obor

Utama, I Gusti Bagus Rai. 2017. Pemasaran Pariwisata. Denpasar: CV. ANDI OFFSET Wahab, Salah. 2003. Manajemen Kepariwisataan. Jakarta: Pradnya Paramita

Widodo, Dukut Imam, dkk. 2006. Malang Tempo Doeloe Djilid Satoe. Malang: Bayoemedia 